\title{
Managing nicotine dependence in NSW hospitals under the Smoke-free Health Care Policy
}

\section{Colin Mendelsohna, b}

a The Sydney Clinic, NSW, Australia

b Corresponding author: mendel@bigpond.net.au

\section{Article history}

Publication date: July 2015

Citation: Mendelsohn C. Managing nicotine dependence in NSW hospitals under the Smoke-free Health Care Policy. Public Health Res Pract. 2015;25(3):e2531533. doi: http://dx.doi.org/10.17061/phrp2531533

\section{Key points}

- Hospitalisation is a powerful 'teachable moment' for smokers

- Smoking cessation support is the responsibility of all medical, nursing and allied health staff

- Hospital-based interventions with at least 1 month follow-up significantly increase long-term quit rates

- Smoking can be addressed using the '5As' model: ask, assess, advise, assist and arrange follow-up

- Nicotine replacement therapy should be offered to all nicotine-dependent smokers to manage cravings and withdrawal symptoms

- A dose reduction of certain drugs may be required after smoking cessation

\section{Abstract}

Under the new NSW Health Smoke-free Health Care Policy, the smoke-free status of public hospital campuses has been reaffirmed and all clinical staff are required to provide routine brief interventions for all smoking patients.

The policy creates a unique opportunity to assist smokers to quit permanently in a supportive environment when motivation to quit is high. Smoking remains the leading cause of preventable death and disability in New South Wales (NSW).

Counselling beginning in hospital and continuing for at least 1 month after discharge significantly increases quit rates. Smoking can be addressed using the 5As model, which includes asking about smoking, assessing readiness to change and nicotine dependence, advising all smokers to quit, assisting smokers to quit and arranging follow-up. Postdischarge support is a vital ingredient for long-term success and should be arranged during the hospital stay.

Nicotine replacement therapy (NRT) should be offered to all nicotinedependent smokers soon after admission. NRT helps manage cravings and nicotine withdrawal symptoms and significantly increases quit rates. Most smokers commence NRT on a nicotine patch, with an oral form of NRT added as required. It is important to give patients detailed instructions on the correct use of NRT and to ensure an adequate dose is taken to relieve symptoms. NRT is well tolerated and can be used perioperatively, during pregnancy and in patients with cardiovascular disease.

Blood levels of certain drugs rise within several days after smoking cessation, so dose reductions may be required. Drugs with a narrow therapeutic index such as clozapine, olanzapine, warfarin and theophylline are of special importance. 


\section{Introduction}

NSW Health has recently revised and reaffirmed its smoke-free policy for all NSW Health buildings, grounds and vehicles with the new NSW Health Smoke-free Health Care Policy. ${ }^{1}$ Since 15 January 2015, all Local Health Districts (LHDs) are required to ensure compliance with the policy and have the power to enforce it with penalty infringement notices for smokers.

The policy outlines the responsibilities of all managers and staff. In particular, public hospital staff are required to undergo smoking cessation training and provide routine brief interventions to all smoking patients.

The new directive aims to deliver a consistent practice in all LHDs across New South Wales (NSW). Under the previous Smoke-free Workplace Policy, implementation of smoking restrictions has been patchy and has progressed slowly in some areas.

Although the prevalence of smoking is declining, $16.4 \%$ of NSW adults (aged $\geq 16$ years) smoked in 2013 , and rates are higher among hospitalised patients. ${ }^{2}$

Smoking remains the leading cause of preventable death and disability in NSW, accounting for around 5500 deaths and 46000 hospitalisations each year. ${ }^{2}$

Being in hospital is a potentially powerful 'teachable moment' for change. ${ }^{3}$ Smokers in hospital are often motivated to quit due to concerns about their health, and most are receptive to smoking cessation advice from hospital staff. ${ }^{4}$ An absence of the normal smoking triggers, and access to health professionals for advice and support, can make quitting easier.

Long-term quit rates are significantly improved by brief hospital-based interventions. ${ }^{5}$ Smokers who quit have immediate and substantial health benefits ${ }^{6}$, improved postoperative recovery ${ }^{7}$, reduced length of stay and lower readmission rates. ${ }^{5}$

Despite these potential benefits, most hospitalised smokers receive suboptimal smoking care. ${ }^{8}$ Inpatient interventions are delivered by busy clinicians in addition to their existing patient care responsibilities, and many do not feel that smoking cessation is part of their role. ${ }^{9}$ However, smoking cessation support is the responsibility of all hospital clinical staff, and effectiveness is improved if treatments are delivered by more than one health professional.

This paper will outline an evidence based and practical approach for use by clinical staff to assist hospitalised smokers, as required under the Smokefree Health Care Policy. This includes a counselling framework and detailed advice about the use of nicotine replacement therapy (NRT). Drug interactions with smoking will also be discussed.

Multiple systemic strategies and organisational support are also required to optimise delivery of smoking cessation interventions, but are beyond the scope of this article.

\section{Effectiveness of hospital-based interventions}

Brief interventions delivered by hospital staff are effective. A Cochrane meta-analysis found that brief counselling that continued for at least 1 month after discharge increased quit rates by $37 \%$ at $6-12$ months follow-up. ${ }^{5}$ Adding NRT to counselling increased cessation rates by a further $54 \% .^{5}$ This compares very favourably with unassisted quit attempts, which have a success rate of $3-5 \%$ after $6-12$ months. ${ }^{10}$

Interventions for smokers having elective surgery can also be effective. A randomised controlled trial at a presurgical clinic at a NSW teaching hospital demonstrated significantly reduced preoperative smoking and increased quit rates after 3 months compared with usual care. ${ }^{11}$

Furthermore, hospital-based smoking cessation interventions are highly cost-effective, especially when compared with many other routine health interventions. ${ }^{12}$

\section{A framework for hospital-based intervention}

All hospitalised smokers should be encouraged and assisted to quit permanently. A comprehensive, evidence based manual on how to manage nicotine dependence ${ }^{13}$ has recently been developed for NSW Health staff and is based on the ' 5 As' framework used in the Australian smoking cessation guidelines. ${ }^{14}$ The key steps of the 5 As are listed below.

Ask

Ask all patients about smoking and record their smoking status in their medical record.

\section{Assess}

Assess smokers for their readiness to quit and the level of nicotine dependence.

Assess readiness to quit by asking, "How do you feel about your smoking?" Smokers thinking about quitting should be encouraged to try to quit for good.

The level of nicotine dependence helps predict the severity of withdrawal symptoms and is a guide to the intensity of treatment required. Ask the patient, "How long after you wake do you have your first cigarette?" Smoking within 30 minutes of waking is a reliable sign of nicotine dependence. Smoking within 5 minutes indicates high dependence.

\section{Advise}

All smokers should be informed of the hospital smoke-free policy and advised to quit in a clear, nonconfrontational, personalised way - for example, "The best thing you can do for your health/asthma/surgical risk is to stop smoking". 


\section{Assist}

All smokers should be offered help to quit, irrespective of their willingness to quit. The most effective way to quit smoking is with a combination of counselling and pharmacotherapy.

Counselling strategies for hospital patients include: ${ }^{14}$

- Providing information (e.g. discussing the personal health benefits of quitting, describing withdrawal symptoms, encouraging exercise and emphasising the 'not-a-puff' rule)

- Identifying smoking triggers and high-risk situations and discussing strategies to cope with them (e.g. change coffee to herbal tea)

- Discussing barriers to quitting such as weight gain, fear of failure, coping with stress or peer pressure

- Encouraging support from family and friends

- Providing printed materials.

NRT is recommended for all smokers who have nicotine dependence, and can be used to aid quitting or to support temporary abstinence.

\section{Arrange}

Follow-up for at least 1 month after discharge is an essential ingredient for long-term success and should be arranged before discharge. Referral options include the patient's general practitioner, Quitline (telephone 13 7848), a tobacco treatment specialist (see www.aascp. org.au) or a smoking clinic. Referrals to NSW Quitline can be made using its fax referral form. ${ }^{15}$ Interventions that do not include follow-up have been shown not to improve success rates. ${ }^{5}$ On discharge, all patients who have been using NRT should be provided with a minimum of 3 days' medication. ${ }^{1}$

\section{Smokers who are not ready to quit}

Smokers who are not willing or ready to quit should be advised to quit and be supported through temporary abstinence in hospital. Most nicotine-dependent smokers will need NRT, because abrupt cessation can trigger nicotine withdrawal and cigarette cravings. Some of these smokers will go on to quit permanently, because a period of temporary abstinence in hospital can increase motivation and self-efficacy. ${ }^{16}$

\section{Nicotine replacement therapy}

NRT is the most appropriate medication in the hospital setting because of its quick action, safety, ease of use and proven efficacy. ${ }^{5,17}$ NRT should be offered to all nicotine-dependent smokers aged 12 and over soon after admission, to manage nicotine withdrawal symptoms and cigarette cravings (see Box 1). Symptoms appear within a few hours of the last cigarette and peak at 48-72 hours.

In most hospitals, NRT can be initiated by nursing staff with sign-off by a doctor within 24 hours. A range of NRT
Box 1. Nicotine withdrawal symptoms

- Irritability, frustration, anger

- Increased appetite and weight gain

- Difficulty concentrating

- Restlessness

- Depressed mood

- Disturbed sleep

Source: Diagnostic and statistical manual of mental disorders, 5th edition (DSM-5)

products should be available in the hospital dispensary to accommodate patient preferences and clinical suitability.

\section{Correct use of NRT}

The nicotine patch is applied daily to the skin and provides continuous protection against background cravings. The oral forms (nicotine mouth spray, oral strips, lozenges, gum and inhalator) give faster, flexible relief for breakthrough (cue-induced) cravings as a result of smoking triggers, such as a cup of coffee (see Table 1).

People who smoke more than 10 cigarettes per day and weigh more than $45 \mathrm{~kg}$ start with a full-strength patch (21 mg/24 hours or $25 \mathrm{mg} / 16$ hours). An oral form of NRT is added if cravings or withdrawal symptoms are not controlled by the patch alone. ${ }^{14}$

Oral NRT products should be taken in anticipation of a smoking trigger if possible, or otherwise when cravings are experienced. The nicotine mouth spray and oral strips give the quickest relief. Oral NRT can also be used on a regular (e.g. hourly) basis.

NRT monotherapy (a single nicotine product) increases quit rates by $60 \%$ compared with placebo. ${ }^{17}$ Combination NRT (a nicotine patch plus an oral agent such as gum or lozenge) increases quit rates by a further $34 \%$ and is well tolerated. ${ }^{17}$

It is vital to instruct patients on the correct use of NRT products (see Table 1) because they are often used incorrectly. ${ }^{18}$ Nicotine from oral products is absorbed through the buccal mucosa and should not be swallowed or inhaled. Smokers should be advised not to drink or eat immediately before and while using any form of oral NRT because this reduces the absorption of nicotine. ${ }^{18}$

In general, patients using NRT receive too little nicotine to satisfy cravings, partly due to misguided concerns about safety, effectiveness and the risk of addiction. Blood nicotine levels from the recommended doses are about one-third to half those of regular smoking, so the initial dose can be safely increased if cravings are not controlled. Higher doses of the oral products have been shown to be safe and significantly increase quit rates. ${ }^{18}$ See Box 2 for a checklist for NRT prescribing. 
Table 1. Nicotine replacement therapy

\begin{tabular}{lllll}
\hline Product & Recommended dose & $\begin{array}{l}\text { Course of } \\
\text { treatment }\end{array}$ & $\begin{array}{l}\text { Common adverse } \\
\text { effects }\end{array}$ & Directions for use \\
\hline Nicotine patch & $\begin{array}{l}\text { Start with a full-strength } \\
\text { patch if usually smoke }\end{array}$ & & $\begin{array}{l}\text { Insomnia, disturbed } \\
\text { dreams (24-h }\end{array}$ & $\begin{array}{l}\text { Apply in morning to upper } \\
\text { arm, chest or back and rotate }\end{array}$ \\
$16 \mathrm{~h}: 21 \mathrm{mg}, 14 \mathrm{mg}, 7 \mathrm{mg}$ & $\begin{array}{l}\text { patch). Skin irritation } \\
\text { application site daily }\end{array}$
\end{tabular}

Nicotine mouth spray

$1 \mathrm{mg}$ per spray

Nicotine oral strips $2.5 \mathrm{mg}$

Nicotine lozenges

$2 \mathrm{mg}, 4 \mathrm{mg}$

Nicotine mini lozenges $1.5 \mathrm{mg}, 4 \mathrm{mg}$

Nicotine gum

$2 \mathrm{mg}, 4 \mathrm{mg}$

Nicotine inhalator 15 mg per cartridge

$1-2$ sprays every
$30-60$ min.
Maximum 4 sprays per
hour or 64 sprays per
day
Initially 1 strip every

Initially 1 strip every 12 weeks 1-2 h, up to 15 per day

12 weeks

Mouth/throat irritation, nausea, dyspepsia, Fast-acting craving relief. Spray under tongue or onto inside of cheek

headache, hiccups

Nausea, throat irritation, hiccups, headache

9-15 lozenges per day. 12 weeks Use $4 \mathrm{mg}$ if TTFC < $30 \mathrm{~min}$

$1.5 \mathrm{mg}: 9-20$ per day 12 weeks $4 \mathrm{mg}$ : 9-15 per day Use $4 \mathrm{mg}$ if TTFC < $30 \mathrm{~min}$

\section{$2 \mathrm{mg}: 8-20$ per day 12 weeks}

$4 \mathrm{mg}: 4-10$ per day

Use $4 \mathrm{mg}$ if TTFC $<30$ min

3-6 cartridges per day 12 weeks
Nausea, hiccups, heartburn, flatulence Nausea, hiccups,
heartburn, flatulenc jaw discomfort, mouth/throat irritation

Cough, mouth/throat Frequent, shallow puffs. Satisfies irritation, nausea hand-to-mouth habit
Fast-acting craving relief for less dependent smokers (TTFC $\geq$ $30 \mathrm{~min})$. Place on tongue and apply to palate. Dissolves in 2-3 min Allow to dissolve in mouth over 20-30 min, moving around from time to time

Allow to dissolve in mouth over 10-15 min, moving around from time to time

Instruct patients on 'park and chew' technique . Avoid in people with dentures

TTFC = time to first cigarette

a Chew gum slowly until peppery taste appears and then place gum in the buccal pouch until taste fades. Chew again until taste appears.

Repeat cycle for 30 minutes, then discard. Avoid swallowing nicotine.

Source: Mendelsohn ${ }^{18}$

\section{Safety of NRT}

Although nicotine is the main cause of dependence on tobacco, it has few significant adverse effects, except in pregnancy. Nicotine is absorbed more slowly from NRT than from smoking and reaches lower peak blood levels. NRT is always safer than smoking.

Adverse effects depend on the delivery system. The patch can cause skin irritation, disturbed sleep and abnormal dreams. The gum can cause jaw pain, and the inhalator and mouth spray can cause throat irritation. Other side-effects from oral treatments include dyspepsia, nausea and hiccups.

The safety of NRT in smokers with stable cardiovascular disease has been firmly established. ${ }^{19}$ There is also growing evidence for the safety of NRT in acute coronary syndromes, and its use in the hospital setting can be considered if patients are unable to abstain from smoking without it. ${ }^{19}$

There is no evidence to support the concern that NRT may impair postoperative wound healing. The current opinion is that the adverse effects of NRT on postoperative outcomes, if they exist, are minimal and harmless. ${ }^{20}$
There is insufficient evidence to determine whether NRT is safe in pregnancy, but available data and expert opinion suggest it is less harmful than continuing to smoke. ${ }^{21}$

\section{Preadmission and outpatient}

\section{settings}

Patients should be encouraged to quit smoking before hospital admission and in outpatient settings wherever possible. In these busy clinical settings, an ask-adviserefer protocol can be delivered in as little as 30 seconds. Where time permits, a recommendation for NRT may increase quit rates further.

Smoking should be addressed routinely at the time of booking or waitlisting for surgery. Surgery represents a teachable moment for quitting, especially when required for diseases related to smoking. ${ }^{22}$ However, very few surgical patients receive smoking cessation interventions preoperatively, and most smokers smoke up to the day of elective surgery. ${ }^{23}$ Smokers know little of their increased surgical risks, and many may quit with simple advice. ${ }^{23}$ 
Box 2. Checklist for prescribing NRT

Assess for nicotine dependence

Check for:

- Precautions: recent cardiovascular event, pregnancy

- Age 12 or older

Explain:

- Rationale for use

- Safety, effectiveness and low risk of addiction

- Possible side-effects

- Correct use (see Table 1)

Start treatment:

- Commence nicotine patch: $21 \mathrm{mg} / 24$ hours or $25 \mathrm{mg} / 16$ hours if the person smokes more than 10 cigarettes per day and weighs more than $45 \mathrm{~kg}$

- Add an oral agent on a regular basis, or when necessary, if cravings persist

- Emphasise the importance of an adequate dose - number of pieces, puffs or sprays per day. If in doubt, use more

- Encourage a full course (at least 8-12 weeks)

Source: Mendelsohn ${ }^{18}$

A Cochrane meta-analysis found that intensive quitting interventions before surgery reduced postoperative complications by $42 \%{ }^{7}{ }^{7}$ Cessation at least 4 weeks before elective surgery is recommended, but longer is better. ${ }^{7}$

Helping smokers to quit should also be a routine part of care in emergency departments and outpatient clinics.

\section{Drug interactions with smoking}

Patients who smoke should be screened on admission for potential drug interactions with smoking. Tobacco smoke induces the activity of the hepatic enzyme CYP1A2, which metabolises a number of clinically important drugs (see Table 2). ${ }^{24}$ After smoking cessation, blood levels of these drugs rise within several days and dose reductions may be required.

Drugs with a narrow therapeutic range, such as clozapine and olanzapine, may require a dose reduction of up to $50 \%$ after quitting. Smokers taking warfarin require a 13\% higher dose than nonsmokers, and close monitoring of the international normalised ratio is recommended after quitting. Caffeine intake should be reduced by half to lessen the risk of caffeine toxicity. In contrast, clopidogrel is less effective after quitting ('the smoker's paradox').

A more comprehensive list of drug interactions is available online. ${ }^{25}$
Table 2. Clinically relevant drug interactions with smoking

\begin{tabular}{lll}
\hline Class & Medication & $\begin{array}{l}\text { Clinical } \\
\text { importance }\end{array}$ \\
\hline Antipsychotics & $\begin{array}{l}\text { Clozapine, olanzapine } \\
\text { Haloperidol, chlorpromazine, } \\
\text { fluphenazine }\end{array}$ & ++ \\
Antidepressants & Fluvoxamine & + \\
& $\begin{array}{l}\text { Duloxetine, mirtazapine, } \\
\text { imipramine }\end{array}$ & + \\
Cardiovascular & $\begin{array}{l}\text { Warfarin } \\
\text { disease }\end{array}$ & $\begin{array}{l}\text { Clopidogrel (significantly less } \\
\text { effective after quitting) }\end{array}$ \\
& $\begin{array}{l}\text { Beta-blockers, verapamil, } \\
\text { flecainide }\end{array}$ & + \\
& Theophylline, insulin & ++ \\
Other & $\begin{array}{l}\text { Benzodiazepines, naratriptan, } \\
\text { ondansetron, some anticancer } \\
\text { drugs }\end{array}$ & + \\
& Caffeine, alcohol & ++
\end{tabular}

Source: Lucas and Martin ${ }^{24}$

\section{Conclusion}

Hospitalisation is a powerful teachable moment for change. All patients should be asked about smoking on admission, and smokers should be encouraged and assisted to quit permanently. The most effective interventions include a combination of counselling and NRT.

Brief interventions that include at least 4 weeks followup after discharge from hospital significantly increase long-term quit rates.

Smoking cessation interventions are the responsibility of all medical, nursing and allied health staff in hospitals and should be integrated into routine clinical practice.

\section{Competing interests}

The author is a member of Pfizer Australia's Advisory Board and has received payment for consultancies, lectures, travel and meeting expenses unrelated to this work from Pfizer, GlaxoSmithKline and Johnson and Johnson Pacific. He has also received payment from GlaxoSmithKline for development of educational presentations for pharmacists.

\section{Author contributions}

$\mathrm{CM}$ was entirely responsible for planning, writing and editing the manuscript. 


\section{References}

1. NSW Health. NSW Health Smoke-free Health Care Policy 2015. Sydney: NSW Health; 2015 [cited 2015 Jan 15]. Available from: www0.health.nsw.gov.au/policies/ pd/2015/pdf/PD2015_003.pdf

2. NSW Ministry of Health. HealthStats NSW. Sydney: NSW Ministry of Health; [cited 2015 Jan 12]. www.healthstats. nsw.gov.au

3. McBride CM, Emmons KM, Lipkus IM. Understanding the potential of teachable moments: the case of smoking cessation. Health Educ Res. 2003;18(2):156-70.

4. Baratiny G, Campbell E, Sanson-Fisher RW, Cockburn J. Hospital patients receptive to quit smoking advice. Health Promot J Aust. 2003;14(1):69.

5. Rigotti NA, Clair C, Munafo MR, Stead LF. Interventions for smoking cessation in hospitalised patients. Cochrane Database Syst Rev. 2012;5:CD001837.

6. Jha P, Ramasundarahettige C, Landsman V, Rostron B, Thun M, Anderson RN, et al. 21st-century hazards of smoking and benefits of cessation in the United States. N Engl J Med. 2013;368(4):341-50.

7. Thomsen T, Villebro N, Møller AM. Interventions for preoperative smoking cessation. Cochrane Database Syst Rev. 2014;3:CD002294.

8. Freund M, Campbell E, Paul C, Sakrouge R, Wiggers J. Smoking care provision in smoke-free hospitals in Australia. Prev Med. 2005;41(1):151-58.

9. Nagle A, Schofield M, Redman S. Australian nurses' smoking behaviour, knowledge and attitude towards providing smoking cessation care to their patients. Health Promot Int. 1999;14(2):133-44.

10. Hughes JR, Keely J, Naud S. Shape of the relapse curve and long-term abstinence among untreated smokers. Addiction. 2004;99(1):29-38.

11. Wolfenden L, Wiggers J, Knight J, Campbell E, Rissel C, Kerridge $\mathrm{R}$, et al. A programme for reducing smoking in pre-operative surgical patients: randomised controlled trial. Anaesthesia. 2005;60(2):172-79.

12. Ladapo JA, Jaffer FA, Weinstein MC, Froelicher ES. Projected cost-effectiveness of smoking cessation interventions in patients hospitalized with myocardial infarction. Arch Intern Med. 2011;171(1):39-45.
13. NSW Ministry of Health. Managing nicotine dependence: a guide for NSW Health staff. Sydney: NSW Ministry of Health; 2015 [cited 2015 Apr 15]. Available from: www. health.nsw.gov.au/quittingsmoking/Pages/managingnicotine-dependence.aspx

14. Zwar N, Richmond R, Borland R, Peters M, Litt J, Bell J, et al. Supporting smoking cessation: a guide for health professionals. Melbourne: The Royal Australian College of General Practitioners; 2014 [cited 2015 Jan 12]. Available from: www.racgp.org.au/your-practice/guidelines/ smoking-cessation/

15. NSW Health. Referral to NSW Quitline. Sydney: NSW Health [cited 2015 Apr 15]. Available from: www.health. nsw.gov.au/quittingsmoking/Documents/quit-referral.pdf

16. Rigotti NA, Arnsten JH, McKool KM, Wood-Reid KM, Pasternak RC, Singer DE, et al. Smoking by patients in a smoke-free hospital: prevalence, predictors, and implications. Prev Med. 2000;31(2 Pt 1):159-66.

17. Stead LF, Perera R, Bullen C, Mant D, HartmannBoyce J, Cahill K, et al. Nicotine replacement therapy for smoking cessation. Cochrane Database Syst Rev. 2012;11:CD000146.

18. Mendelsohn C. Optimising nicotine replacement therapy in clinical practice. Aust Fam Physician. 2013;42(5):305-9

19. Mendelsohn C. Smoking and cardiovascular disease. Cardiology Today. 2013;3(4):23-5.

20. Sorensen LT. Wound healing and infection in surgery. The clinical impact of smoking and smoking cessation: a systematic review and meta-analysis. Arch Surg. 2012;147(4):373-83.

21. Mendelsohn C, Gould GS, Oncken C. Management of smoking in pregnant women. Aust Fam Physician. 2014; 43(1):46-51.

22. Shi Y, Warner DO. Surgery as a teachable moment for smoking cessation. Anesthesiology. 2010;112(1):102-7.

23. Webb AR, Robertson N, Sparrow M. Smokers know little of their increased surgical risks and may quit on surgical advice. Aust NZ J Surg. 2013;83(10):753-7.

24. Lucas C, Martin J. Smoking and drug interactions. Australian Prescriber. June 2013;36(3):102-4.

25. NSW Health. Medication interactions with smoking and smoking cessation. Sydney: NSW Health; 2012 [cited 2015 Apr 12]. Available from: www.health.nsw.gov.au/ tobacco/Publications/tool-14-medication-intera.pdf

\section{Copyright: (c) () (2)}

(C) 2015 Mendelsohn. This article is licensed under the Creative Commons Attribution-NonCommercial-ShareAlike 4.0 International Licence, which allows others to redistribute, adapt and share this work non-commercially provided they attribute the work and any adapted version of it is distributed under the same Creative Commons licence terms. See: www.creativecommons.org/licenses/by-nc-sa/4.0/ 